Original Research Paper

\title{
Development of Attendance Monitoring System with Artificial Intelligence Optimization in Cloud
}

\author{
Mohamad Fakir Naen ${ }^{1}$, Muhamad Hariz Muhamad Adnan ${ }^{2 *}$, Nurul Adilah Yazi ${ }^{1}$, Chee \\ Ken Nee ${ }^{1}$ \\ ${ }^{1}$ Department of Computing, Faculty of Arts, Computing and Creative Industry, \\ Universiti Pendidikan Sultan Idris. Tanjung Malim, Malaysia. \\ ${ }^{2}$ National Child Development Research Centre, Universiti Pendidikan Sultan Idris. \\ Tanjung Malim, Malaysia.
}

Article History

Received:

08.11.2021

Revised:

20.12.2021

Accepted:

23.12.2021

*Corresponding Author:

Muhamad Hariz Muhamad

Adnan

Email

mhariz@fskik.upsi.edu.my

This is an open access article, licensed under: $\mathrm{CC}-\mathrm{BY}$-SA

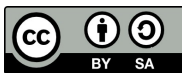

Abstract: The creation of an attendance management system based on biometrics is proposed in this research. Keeping track of student attendance during lecture periods has proven to be a difficult task. Because human calculating creates errors and wastes a lot of time, the capacity to compute the attendance percentage becomes a key challenge. For this reason, a biometricbased attendance management system is being developed. This system uses a fingerprint device to take attendance electronically, and the attendance records are kept in a database. Following student identification, attendance is recorded. Artificial intelligence is also proposed as a component of the system. The system will aid in the reduction of errors and the more effective compilation of attendance data.

Keywords: Artificial Intelligence, Attendance Monitoring System, Biometric, Cloud. 


\section{Introduction}

Academic institutions' present technique of taking student attendance, which involves utilising an attendance book or paper, is insecure. Students may be able to cheat using this strategy. Aside from that, during circulation, the attendance form is frequently misplaced or lost. Taking attendance takes time as well. As a result, a new and modern method of efficiently and effectively tracking and controlling attendance records of students in higher education is required.

The required solution would be a biometric-based automatic attendance management system. An attendance management system is software that is used in schools and institutions to track daily student attendance. It makes it easier to look up a certain student's attendance in a specific class. Individuals will run their thumb over the fingerprint scanner instead of signing an attendance sheet, and the fingerprint will be verified against a list of pre-registered users, and if a match is made, the individual will be logged as having attended that lecture. This system will also assist in the generation of reports and the evaluation of a student's attendance eligibility. Furthermore, parents can receive telegram notifications when their children join the classroom.

Such a system has been developed before. However, an attendance monitoring system using a biometric has not been widely utilized in primary and secondary school and higher learning institutions. This calls for an investigation. This paper investigates the fingerprint attendance systems and proposes an attendance monitoring system with biometric and artificial intelligence optimization in the cloud.

\section{Related Work}

This section discusses numerous past efforts on fingerprint attendance systems that were done as part of previous research. The most common method of keeping track of student attendance in the classroom is to require students to sign an attendance sheet that is passed around the room while the lecturer is giving the lecture [1]. Some pupils may inadvertently or knowingly sign the name of another student. Another disadvantage of using a hardcopy form to obtain an attendance record is that a teacher may misplace the attendance sheet. Another example is when a teacher calls out the names of the students and stamps their presence after they have responded [2]. Manually taking and maintaining attendance records becomes quite inconvenient [3].

Biometrics technology can help overcome these issues, and a proposed fingerprint-based attendance system would be perfect for use in colleges for identification and by businesses for employee attendance tracking [4]. Biometric technology identifies a person as a unique individual based on physiological or behavioural traits [5]. The fingerprint, face, hand vein, hand geometry, iris, retinal pattern, voice print, signature, and facial thermograms are among the nine basic biometric procedures that are frequently utilised [6]. A study of several biometric approaches revealed that fingerprint biometrics is a reliable, mature, and legally recognised biometric technique [7]. The attendance management system is depicted in Figure 1 as a broad block diagram.

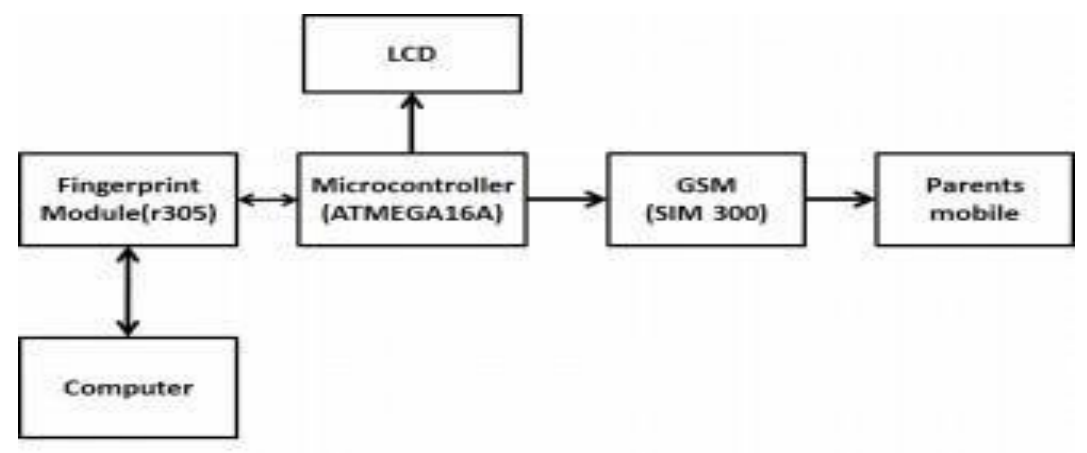

Figure 1. The Attendance Management System is depicted as a Block Diagram [8]

A system was proposed that was built with an Arduino UNO and an optical fingerprint acquisition module [9]. The Wi-Fi module is utilised to send data to the backend server right away. The data, 
which is the student ID, will be decrypted using the Wi-Fi Module and transferred to the access point. The database's attendance information is used to generate a variety of reports, including specific day attendance, current-day attendance, monthly attendance, weekly attendance, entire attendance, and real-time attendance.

To address the issue of bogus attendance, a wireless fingerprint attendance control system was proposed, combining biometrics and wireless technology [3]. The enrolment of fingerprints was conducted on the server using the Digital Persona Fingerprint USB Sensor, and the verification was completed on the client utilising the network transfer of fingerprint templates. An attendance record was generated automatically under this system, and it was subsequently forwarded to faculty members through email. For absenteeism, an SMS was sent to the parent's phone.

An effective Web-based application for tracking students' participation in class was proposed for the attendance management system [10]. The attendance records were saved in a database using this application, which took attendance online. Model, View, and Controller (MVC) architecture was employed in the system design, which was developed using the Laravel Framework. To make the system more user-friendly, JavaScript was added to it. For the Application Database, MySQL is used. Because the rates of theoretical and practical lessons fluctuate, the system is designed to separate the hours of theoretical and practical lessons when computing the percentages of students' absences. Insertions, removals, and updates to data in the system can be done without interacting with the tables using the designed GUI. The system may provide information in a variety of formats.

A smart attendance system that automatically monitors and manages the attendance of students in an educational institution was proposed [11]. The system was designed to make automated analyses and prepare a detailed report weekly, monthly and annually. The whole system is developed with an Arduino microcontroller and RFID readers. Also, GSM and Wi-Fi communication modules are used to make convenient communication depending on the availability of the network. A microchip (microSD) is placed to store data in case of communication failure and those stored data will be uploaded bulk when the communication channel is restored. This system will reduce a lot of manual work of educators and education administrators of an educational institution.

A touchless temperature measuring and attendance monitoring system for the pandemic COVID19 was proposed [12]. This system is built using Node MCU, MLX90614 Infrared Thermometer, RFID Reader, and Ultrasonic Sensor. It measures body temperature with an infrared temperature sensor without any physical contact. An RFID card reader is used for scanning the identity card. The ID number and the temperature of students are uploaded to the webpage. An Ultrasonic Sensor is used to measure the distance between the sensor and the person. The temperature sensor can measure the temperature when the distance between the sensor and person is around $10 \mathrm{~cm}$ for better accuracy.

A system use of intelligent systems in classrooms for recording students' attendance was proposed [13]. The system is linked to RFID technology, face detection mechanism and also based on the location of student's registered mobile device to record the student attendance. RFID is one of the popular identification technologies used since it is cost-effective and sustainable. Along with RFID, biometric face detection and location capturing (ethernet router log) makes this system fully trustworthy. Because of the pandemic COVID-19, a contactless temperature measurement and attendance tracking device has been proposed [12]. The Node MCU, MLX90614 Infrared Thermometer, RFID Reader, and Ultrasonic Sensor were used to create this system. It uses an infrared temperature sensor to assess body temperature without making physical touch. The identity card is scanned using an RFID card reader. Students' ID numbers and temperatures are uploaded to the website. The distance between the sensor and the individual is measured using an ultrasonic sensor. For improved accuracy, the temperature sensor able to measure the temperature for estimate $10 \mathrm{~cm}$ distance between the sensor and the human.

A technique for recording students' attendance using intelligent systems in classrooms was proposed [13]. To record student attendance, the system uses RFID technology, a facial detection mechanism, and the location of the student's registered mobile device. RFID is a popular identifying technology because it is both cost-effective and long-lasting. This system is entirely trustworthy and provides a robust platform for the attendance tracking system, thanks to RFID, biometric face identification, and position capturing (ethernet router log).

To assess and monitor involvement in educational institutions, a biometric-based participation monitoring system was presented [14]. This proposed solution, which uses face recognition, will assist in maintaining all information about current pupils in a classroom and saving it in the class database. The camera takes the image of the students and compares it to the database's existing visual 
data. If the software cannot identify a match for the acquired data in the student database, the student will be listed as absent. Queuing Petri nets assist in meeting the specific needs of distinct institutions while also improving hold-up time performance. Every hour, classroom participation is recorded and kept thanks to the use of this technology.ith this provides a robust platform for the attendance monitoring system.

The attendance monitoring system now uses facial recognition [15]. This process begins with the creation of a classroom image database, which is then used to train the system. The camera is subsequently set at the focal point in the classroom and images are collected, then student faces are recognised from the captured images and compared to the database, and finally, attendance is noted based on the faces identified, the:

\section{students'/parents'/faculty's/teachers'/parents'/teachers'/parents'/parents'/parents'/parents'/parents'/}

Faces are detected using the Haar cascade classifier, and collected photos are compared to the database using a local binary pattern histogram approach. The Raspberry Pi 3B is used to implement the facial recognition system.

The shortcomings of the old attendance system, which is still widely used in poor nations, were addressed with the implementation of a cloud-based biometric attendance system [16]. The cloudbased attendance system authenticates attendance using a fingerprint recognition system, shows user identity on an Organic Light Emitting Diode (OLED) display, and uploads processed attendance data to the cloud using the ESP32 microcontroller and accompanying development board. The system only authenticates and processes the attendance of preregistered candidates whose fingerprints match those pre-stored at the time of collecting attendance, and then uploads the result to the cloud for remote access by the administrator.

\section{Research Methodology}

This research postulated five activities that are depicted in Figure 2.

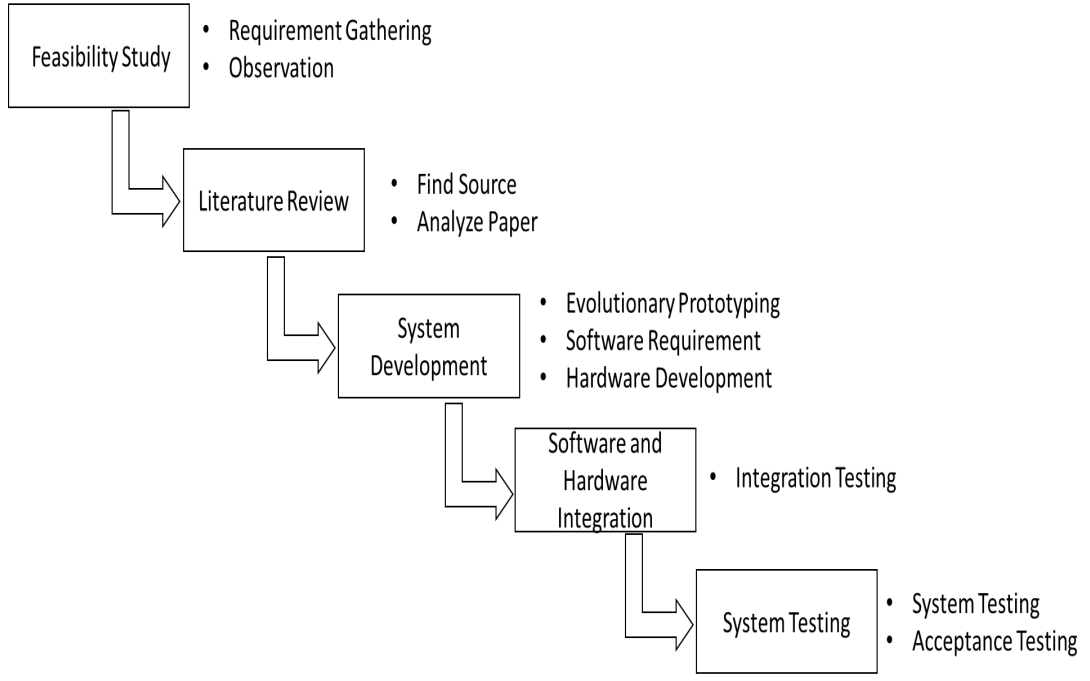

Figure 2. The research activities

The activities are feasibility study, literature review, system development, software and hardware integration and system testing.

In the feasibility study, the requirement was gathered, and observations were made to understand thoroughly all aspects of a project, concept, or plan. In the literature review, information about the related study areas was gathered. In the system development activity, the author used evolutionary prototyping as a system development life cycle (SDLC) for this system. Subsequently, the researcher integrated the software developed and the fingerprint sensor hardware. Lastly, the system was tested. 


\section{Proposed Attendance Monitoring System}

Figure 3 provides an architectural overview of the Framework of System Attendance Management System (SAMS).

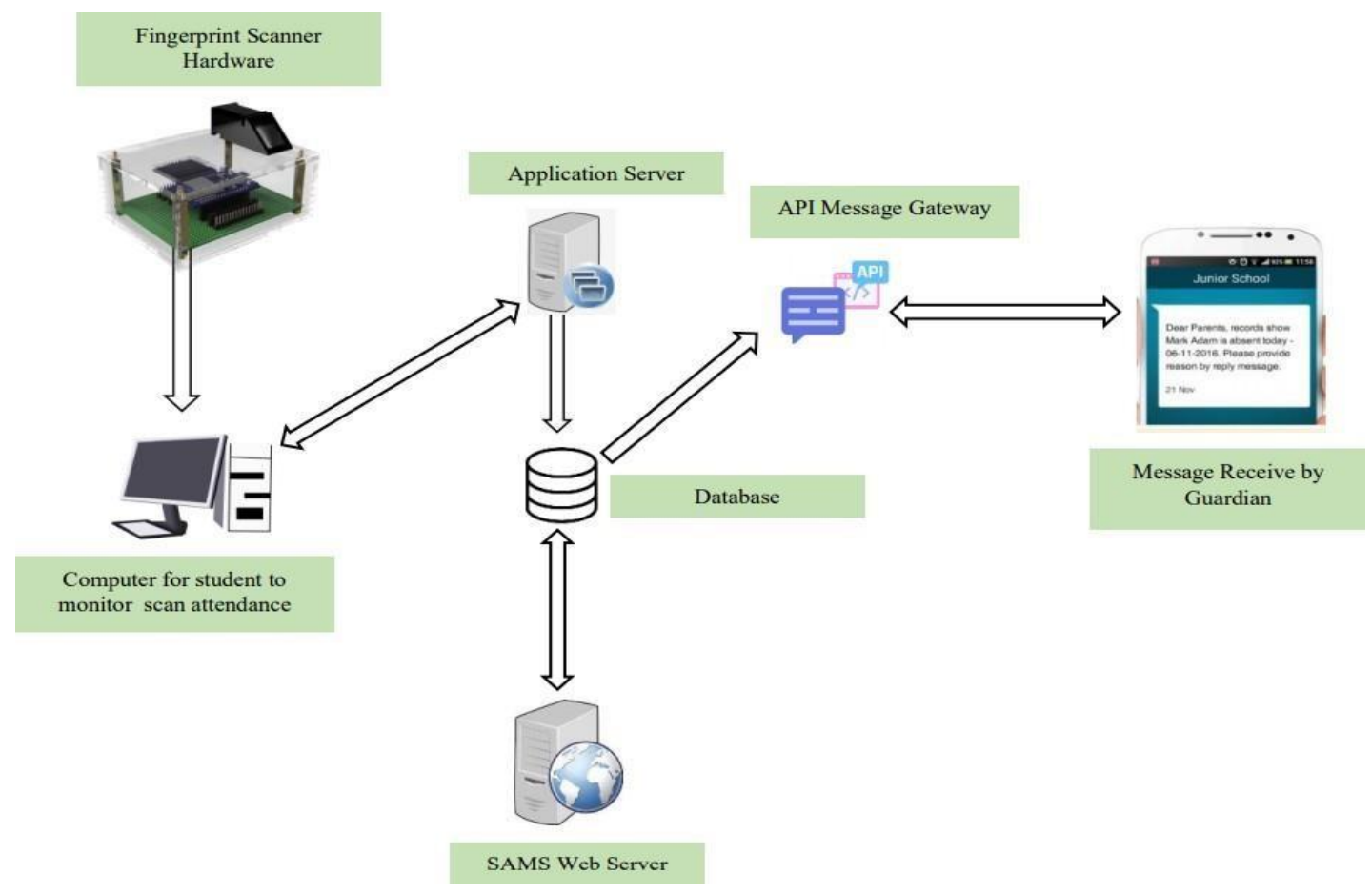

Figure 3. Framework for SAMS

In practise, each classroom has a fingerprint scanner that is connected to the computer using RS232 or RS-485 communication protocols. According to the flow chart, the classroom computer contains an attendance application written in ASP.net that interfaces with several existing attendance modules and matches the information collected from the database server with a fingerprint.

This application will use the school network to communicate with the database server:

- Open Database Connectivity is used to communicate between the database server and the application (ODBC).

- Fingerprint readers must search a database for a match, and this dwell time for students entering a classroom must be minimised.

- The SMS Server is linked to the database of your choice. Oracle, MS Server, PHP, or MySQL can all be used as databases.

- The SMS server will automatically deliver brief messages to the parent's mobile phone over the ODBC connection. SMS is based on the standard organisation of network parts, with the SMS360 service provider integrating APIs.

Figure 4 illustrates how to connect an OLED Display and a Fingerprint Sensor to a NodeMCU ESP8266 12E Board.

The OLED Display's SDA and SCL I2C pins are connected to NodeMCU D2 and D1 pins, respectively. The fingerprint sensor is linked to UART pins D5 and D6 in the same way. The colour of the $T x$ and $R x$ wires on the fingerprint sensor may vary. In my situation, the colours are yellow and blue, with yellow representing $T x$ and blue representing Rx. Otherwise, the module will not be identified by NodeMCU unless you connect it with the appropriate colour wires. The R305 fingerprint sensor receives $5 \mathrm{~V}$ from the NodeMCU's Vin pins. 


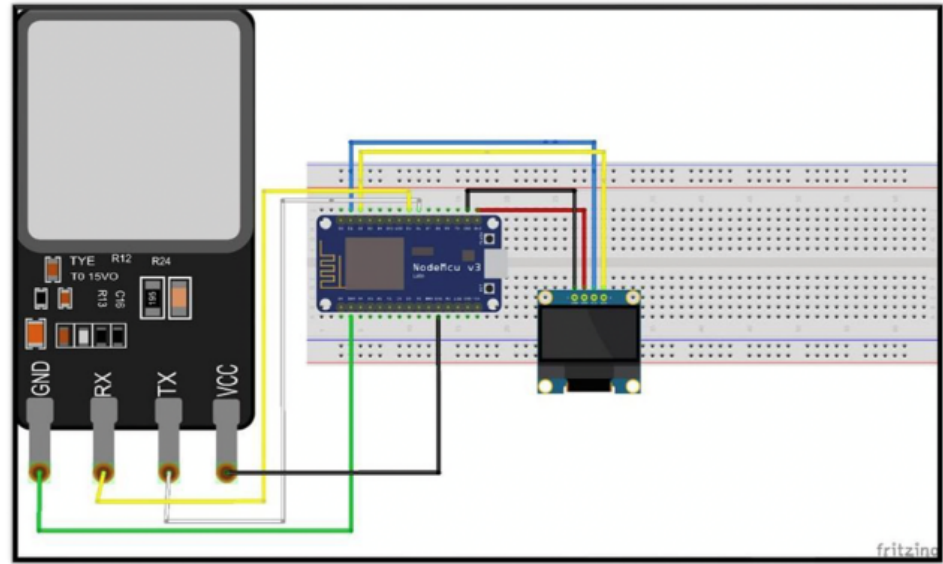

Figure 4. Breadboard Diagram for Hardware

Figure 5 and 6 shows the login and dashboard interface for SAMS.

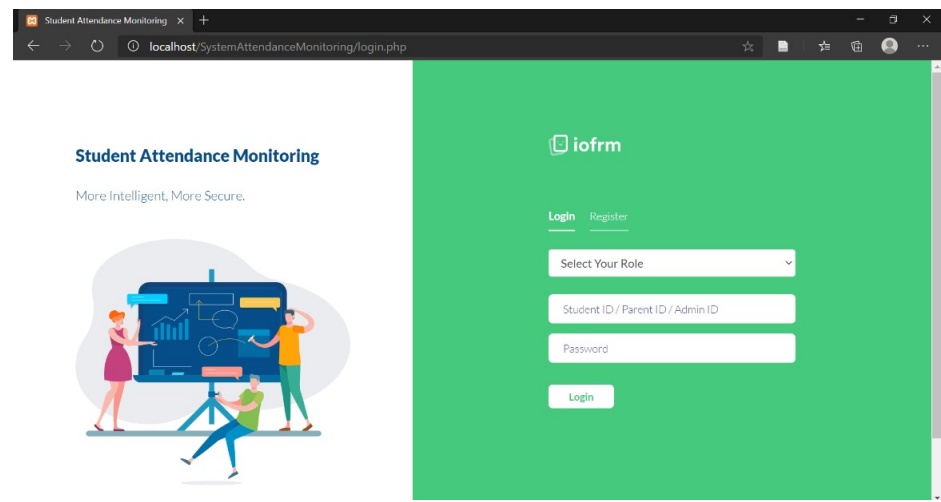

Figure 5. Login panel

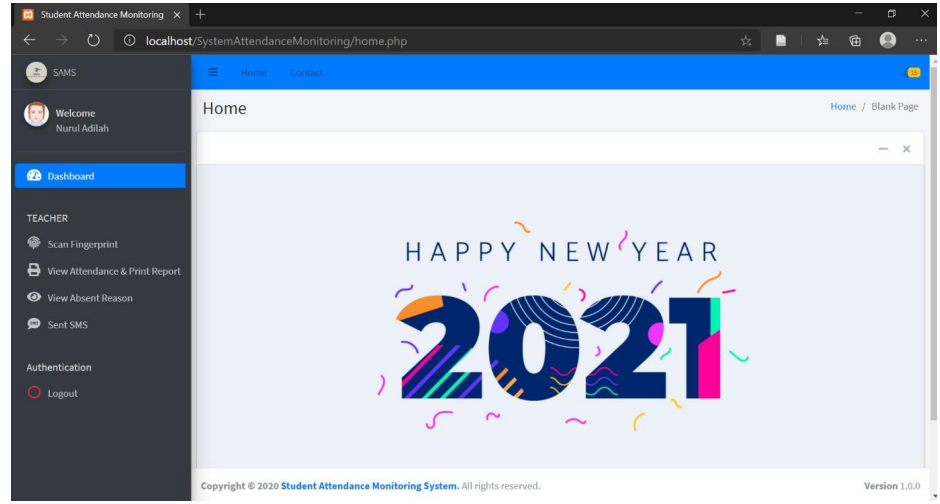

Figure 6. Teacher dashboard

There are four modes of operation to choose from which are Administrator, Teacher, Student, and Parents as shown in the figure below. The administrator mode is utilised by administration personnel who are in charge of monitoring information about students, parents, and teachers. The teacher can monitor the student's attendance, view absent reasons, view the attendance, and send the notification from API message to the parents. Besides that, the teacher can easily spot students who are late as the 
system will display the time when student scan their fingerprints for the verification process. Figure 7 and 8 show the Add ID User interface for SAMS.

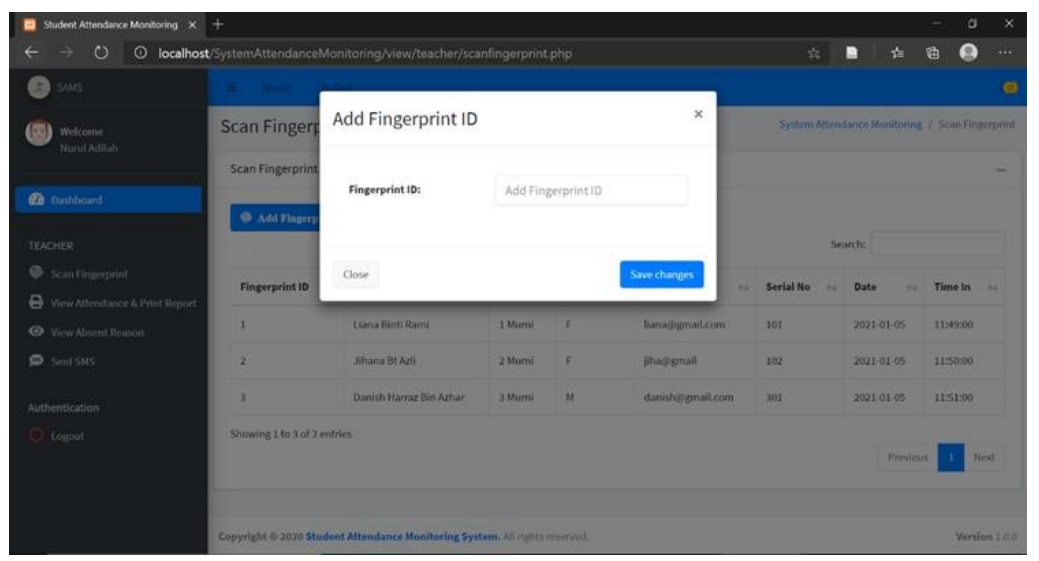

Figure 7. Add ID

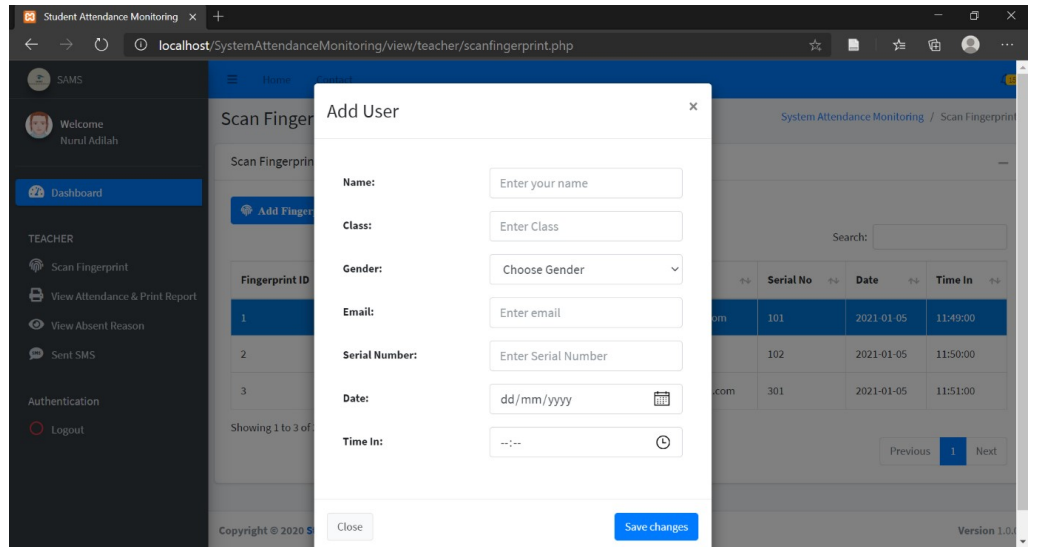

Figure 8. Add User

Figure 9 and Figure 10 show the View attendance and absent reason interface for SAMS.

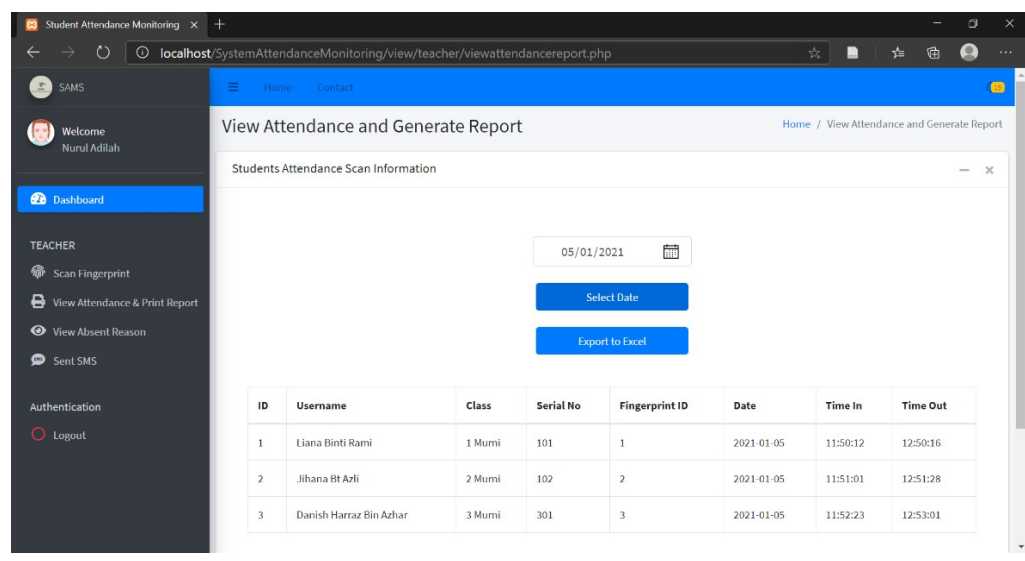

Figure 9. View Attendance 


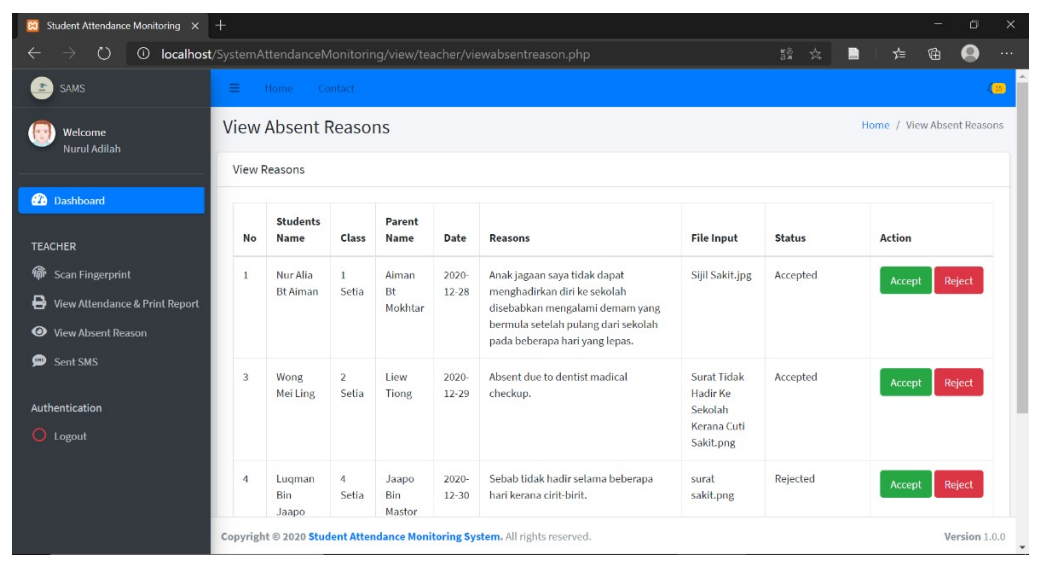

Figure 10. View Absent Reason

The teacher can view the attendance records and generate an excel report. If pupils are absent, parents can provide an attendance explanation to explain why their children are absent, along with an attachment of an upload file. The teacher then has the option of accepting or rejecting the justification.

Artificial Intelligence (AI) is primarily concerned with developing technology that allows machines to emulate human behaviour. AI is used to power learning algorithms. Machine learning, in particular, is critical because it allows algorithms to be improved based on their experience. Artificial neurons are used in neural networks, which are a set of algorithms. Artificial neurons will be modelled after biological neurons. Artificial Neural Networks can be used to solve real-time challenges (ANN).

A basic neuron $\mathrm{N}$ takes input from other neurons before activating itself and modifying its weights with training samples. ANN is the foundation of deep learning, which is a subset of machine learning. $\mathrm{CNN}$ (Convolutional Neural Network) is a type of deep neural network that is frequently employed in a variety of applications. CNN is used in the proposed system to track the kids' contactless attendance. CNN has a variety of pre-trained models for various applications. Pre-trained models (Inception V3) are utilised as the foundation for computer vision in transfer learning. All of the faces' features are extracted and saved separately. When a pupil enters the classroom, the camera detects his or her face in real time. Figure 12 depicts the full procedure.

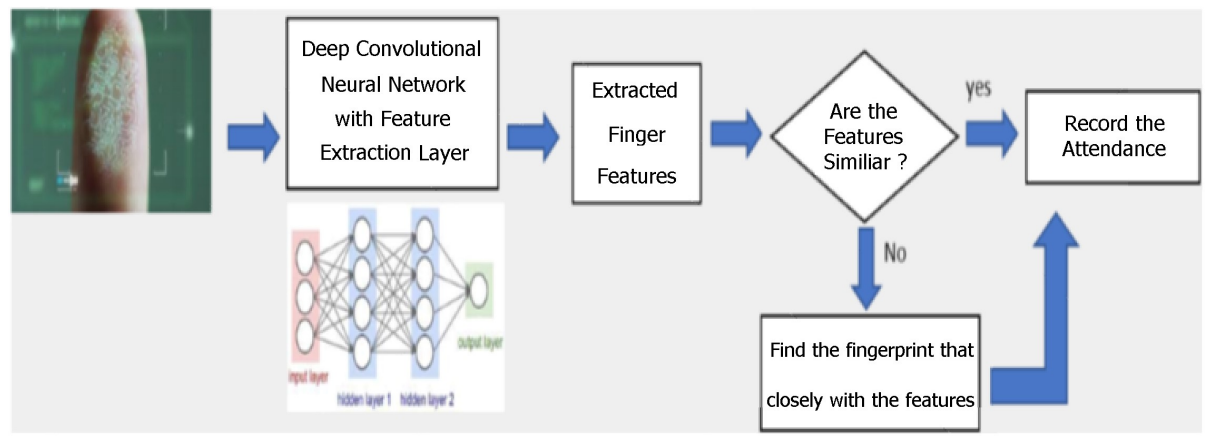

Figure 12. Neural Network in Attendance Monitoring System

With the application of CNN in the attendance monitoring system, the system will be more efficient and accurate. For example, if the fingerprint detector cannot detect the finger that has been scanned. With CNN, it can find data that closely match the finger feature. This is possible because each student's data has been stored in the database on the first day they register for the subject. 


\section{Result and Discussion}

A survey of thirty-three parents and guardians was done to evaluate the user acceptance test on the SAMS system. The participants were allowed to utilise and study the system on their own during the trial. Then there are three sections in which you must complete a series of questionnaires, each of which contains 10 questions and is separated into different categories. The study was successful in evaluating the effectiveness of the system and categorising it into three parts: user interface satisfaction, system usability, and SMS notification integration (ISN). For each sort of criteria discovered, a score value was assigned on a scale of 1 to 5. Yes, Maybe, and No are represented by each scale. Figure 13 depicts the outcome of the SAMS product's functionality.

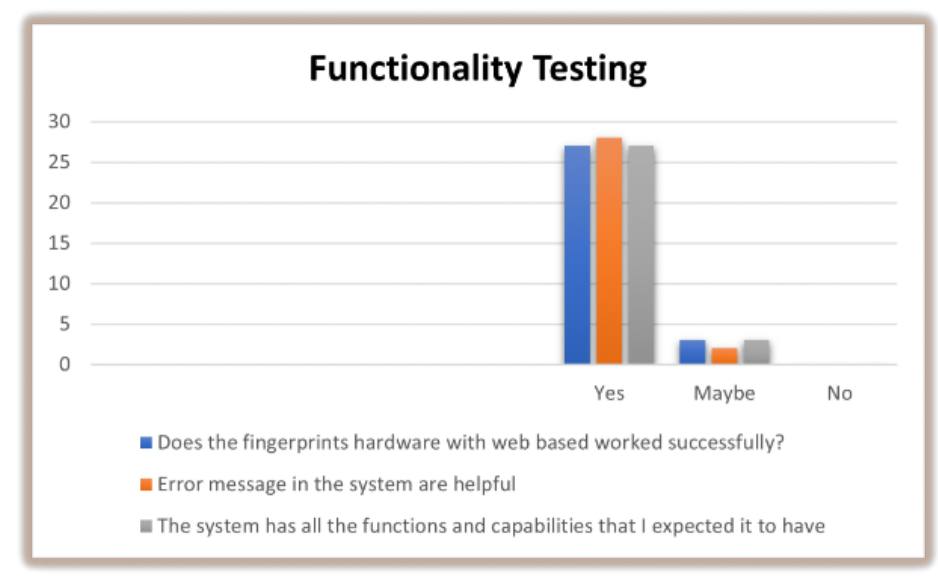

Figure 13. Testing Result: Functionality

The target user evaluated the functional performance of the product. Based on Figure 5, the overall result has shown that from 30 respondents $87.7 \%$ respond 'yes' indicate it reaches the target which is the functionality of the SAMS is excellent. Meanwhile, $12.2 \%$ response maybe indicate some of them did not sure about their opinion. So, it means the functionality of the SAMS gives a positive impact on the users to manage the attendances and to use this project that integrated with the web-based. Figure 14 shows the result of the Usability of the SAMS product.

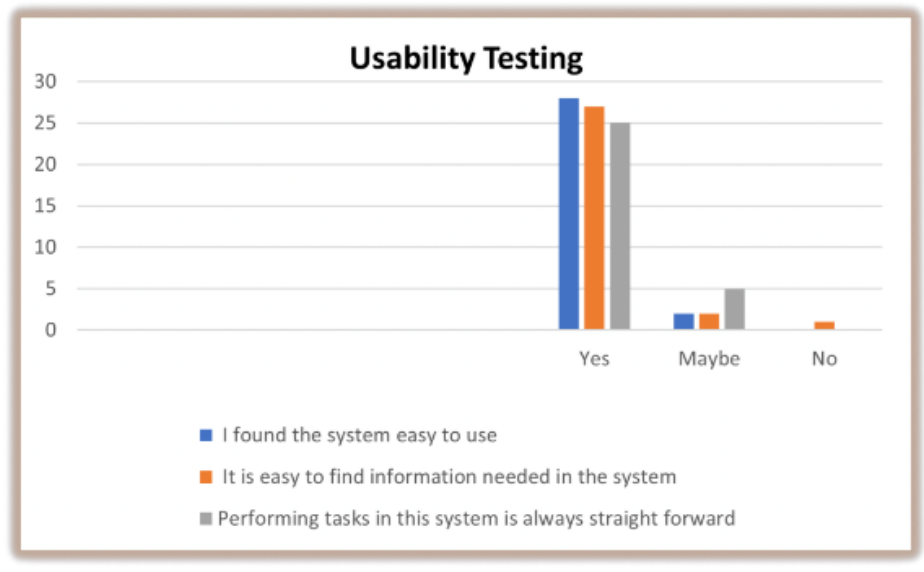

Figure 14. Testing Result: Usability

Based on Figure 6, 27 out of 30 respondents answered strongly agree with the first question, while the other responded to the next options answer. From the second and third questions, most of the 
respondents respond to the 'yes' to the usability testing section. From the mean calculation for all the questions in usability testing, the percentage of the respondents that respond 'yes' is the highest which is $86.6 \%$ while $12.2 \%$ responded 'maybe' and the rest of $1.1 \%$ respond 'no' because it feels difficult to find information needed in the system. Figure 15 shows the result of the Integration of SMS(ISN) respondents of the SAMS product.

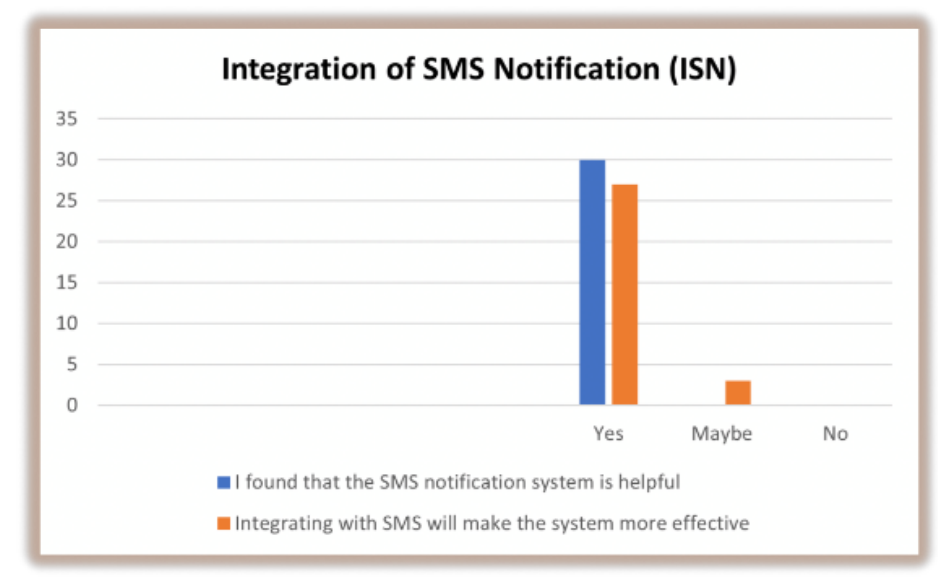

Figure 15. Testing Result: ISN Respondent

Figure 7 depicts the respondents' responses. The majority of them said yes, which means that 30 people think the SMS notification is useful. The addition of SMS notification, on the other hand, is said to make the system more effective by 26 respondents. From this, the maximum proportion of total respondents for two questions was calculated: 93.3 percent of respondents answered 'yes,' while 6.6 percent responded 'no.'

\section{Conclusion}

A fingerprint recognition attendance system can be developed to replace the old attendance method that many educational institutions currently employ. This method is intended to improve the reliability, convenience, efficiency, and accuracy of the entire attendance-taking process. Aside from that, combining biometric technology with a web-based system will help to reduce errors and improve the efficiency with which attendance data can be produced.

\section{Acknowledgements}

The author would like to thank Universiti Pendidikan Sultan Idris and the Institute of Postgraduate Studies of Universiti Pendidikan Sultan Idris for supporting this study.

\section{References}

[1] Z. N. Soe, A. M. Win, and D. T. H. Thoung, "Implementation of Fingerprint based Student Attendance System with Notification by GSM Module," International Journal of Science and Engineering Applications, vol. 7, no. 9, pp. 260-264, 2018.

[2] K. Krishnamurthi, S. I. Mary, B. N. Sumalatha, and A. Pereira, "Fingerprint Based Attendance System," International Journal of Advanced Research in Computer and Communication Engineering, vol. 4, no. 3, 2015. doi: 10.17148/IJARCCE.2015.43149

[3] B. N. Mohapatra, J. Dsouza, Y. Sangoiy, and N. Shah, "Smart attendance system using real time face recognition," International Journal of Technology, vol. 8, no. 1, pp. 1, 2018. doi: 10.5958/2231-3915.2018.00001.9

[4] M. P. Patil, A. Khachane, and P. V. Purohit, "A Wireless Fingerprint Attendance System," International Journal of Security, Privacy and Trust Management (IJSPTM), vol. 5, no. 4, 2016. doi: $10.5121 / \mathrm{ijsptm} .2016 .5402$ 
[5] K. Dharavath, F. A. Talukdar, and R. H. Laskar, "Study on biometric authentication systems, challenges and future trends: A review." in IEE International Conference on Computational Intelligence and Computing Research, 2013, IEEE. doi: 10.1109/ICCIC.2013.6724278

[6] I. Journal, H. Walia, and N. Jain, "Fingerprint Based Attendance Systems-A Review" International Research Journal of Engineering and Technology, vol. 8, no. 12, 2016.

[7] I. Justina, "Fingerprint-Based Authentication System for Time and Attendance Management," British Journal of Mathematics \& Computer Science, vol. 5, no. 6, pp. 735-747, 2015.

[8] V. Desai, Y. Gore, S. Jankar, and S. V. Patil, "Attendance Management using Biometrics with SMS Alerts," International Journal for Research in Applied Science \& Engineering Technology, vol. 6, no. 1, 2018.

[9] S. N. Rahman, S. S. Bashar, Md. A. al Mahmud, Md. S. Miah, A. H. M. Z. Karim, and M. Marium, "A Security System for Kindergarten School Using RFID Technology," Journal of Computer and Communications, vol. 7, no. 4, pp. 21-30, 2019.

[10] G. Singh, R. Dwivedi, and A. Anand, "Attendance monitoring and management using QR code based sensing with cloud based Processing," International Journal of Scientific Research in Computer Science Applications and Management Studies IJSRCSAMS, vol. 8, no. 5, 2019.

[11] P. Kovelan, N. Thisenthira, and T. Kartheeswaran, "Automated Attendance Monitoring System Using IoT," International Conference on Advancements in Computing (ICAC), 2019.

[12] S. Tamilselvan, R. Ramesh, R. Niveda, P. Poonguzhali, and S. Dharani, "IoT based Touch-free Attendance System (ITAS)," in Journal of Physics: Conference Series, 2021, IEEE.

[13] P. Agarwal, V. K. Shukla, R. Gupta, and S. Jhamb, "Attendance Monitoring System Through RFID, Face detection and Ethernet Network: A Conceptual Framework for Sustainable Campus," in 2019 4th International Conference on Information Systems and Computer Networks (ISCON), 2019, pp. 321-325, doi: 10.1109/ISCON47742.2019.9036209.

[14] V. B. Kirubanand, "An enhanced biometric attendance monitoring system using queuing petri nets in private cloud computing with playfair cipher," Journal of Advanced Research in Dynamical and Control Systems, vol. 12, no. 5, pp. 459-468, 2020.

[15] V. Ruhitha, R.V.N. Prudhvi, and G. Geetha, "Implementation of IOT based attendance management system on raspberry pi," in Proceedings of the International Conference on Intelligent Sustainable Systems, 2019, pp. 584-587.

[16] M. D. Rahmatya, M. F. Wicaksono, H. O. Lasisi, B. R. Ajibade, O. C. Ajayi, O. O. Obiyemi, S. C. Thakur, and E. Adetiba, "Implementation of cloud-based biometric attendance system for educators in a developing country," in Journal of Physics: Conference Series, 2034, 12018. (2021). https://doi.org/10.1088/1742-6596/2034/1/012018 